\title{
JEZZYKOZNAWSTWO
}

Наталья Авина

DOI $10.15290 /$ sw.2020.20.10

Университет Vytautas Magnus

Образовательная Академия (Вильнюс)

tel.: +48 852790281

e-mail: nataljaav9@gmail.com

ORCID ID: https://orcid.org/0000-0002-7522-5138

\section{Активные процессы во фразеологии (на материале русскоязычных газет Литвы)}

Ключевые слова: фразеология, активные процессы, региональные особенности, тексты газет

\section{1. Вводные замечания}

Активные процессы, происходящие во всех сферах функционирования русского языка новейшего периода, наиболее ярко проявляются в языке средств массовой информации [см. об этом, например: Русский язык конца ХХ столетия 1996]. Изменения в языке современных СМИ «велики и значимы и представлены многопланово: на содержательном, семантическом и стилистическом уровнях, а также в перераспределении средств общего языка» [Дускаева 2003, 674]. Публицистический дискурс становится «актуальным объектом лингвистических исследований, поскольку этого требует не только все возрастающая прагматическая и информационная значимость средств массовой информации в современной жизни, но и собственно лингвистическая ценность их языка - языка, насыщенного повышенной экспрессивностью» [Мокиенко 2017, 26]. В публицистическом дискурсе активизируются такие процессы, как: авторская индивидуализация; коллоквиализация и стилистический динамизм современного публицистического текста, включающий сочетание контрастных стилистических элементов; повышенная эмоциональность и оценочность; заметное увеличение использования 
юмора и иронии в текстах СМИ - и в этом значительна роль фразеологии [см., например, Стернин 2003].

Как отмечает В.Н. Мокиенко [2017], экспрессивность, генерируемая различными динамическими процессами семантики и структуры фразеологических единиц (ФЕ), - одна из существенных характеристик фразеологии. Фразеология, образность которой оказывает сильное эмоциональное воздействие на читателей, занимает особое место в ряду выразительных средств языка СМИ. Стилевая разнородность ФЕ предоставляет большие возможности для авторского самовыражения.

Активное использование фразеологизмов в масс-медиа обусловлено основными функциями СМИ - информативной и воздействующей, а «фразеология предстает как органичное явление языка СМИ, являющееся средством номинации и создания экспрессии высказывания, что способствует особой выразительности медийного языка» [Баско 2016, 5]. Однако следует согласиться с тем, что, «оценивая роль фразеологии в публицистическом тексте, нельзя констатировать ее высокую употребительность в этих текстах «вообще». Даже сама частотность употребления ФЕ, не говоря уже о семантическом качестве различных групп фразеологии, прямо зависима от функциональной заданности текста, от его тематического и идейного сюжета и от его социальной направленности» [Мокиенко 2017, 28].

Возросшая употребительность фразеологизмов в языке российских СМИ обусловливает актуальность исследования активных процессов во фразеологии, которые рассматриваются в работах В.Г. Костомарова [1994], В. Шапошникова [1998], К. Венцель [1998], Н.В. Баско [2016], В.М. Мокиенко [2017], в коллективной монографии «Славянская фразеология в современных СМИ» [2017] и мн. др. Особый интерес исследователей вызывает специфика русского языка СМИ в различных ситуациях иноязычного окружения [Павловская 2000, Протасова 2004, Зеленин 2006 и др.].

Цель данной статьи - рассмотреть некоторые проявления активных процессов фразеологии в русскоязычных газетах Литвы. Конкретные задачи исследования: определить специфику употребления, структурно-типологические, функционально-стилистические, культурно-речевые особенности $Ф Е$ в текстах современных газет. Материалом статьи являются публикации из еженедельников «Литовский курьер», «Обзор», «Экспресс-неделя» (условные сокращения: ЛК, Обз., Эк.Н.) в период последнего десятилетия (преимущественно 2017-2019 гг.). Основные методы исследования: метод сплошной выборки примеров, описательно-аналитический, классификационно-типологический, 
интерпретативный. Общий объем анализируемых примеров - около 350 контекстных употреблений ФЕ.

В связи с анализируемым материалом представляется необходимым уточнить вопрос о границах фразеологии, который в современной лингвистике остается дискуссионным. В российском языкознании рассматриваются разнообразные структурно-семантические типы ФЕ: вслед за В.В. Виноградовым многие исследователи выделяют такие фразеологические обороты, как сращения, единства, сочетания, выражения; включение же во фразеологический состав пословиц, поговорок, крылатых выражений спорно [см. об этом, например, Телия 1998]. В нашей работе используется широкое понимание фразеологизмов и, соответственно, рассматриваются все типы устойчивых сочетаний. В их ряду особой спецификой характеризуются трансформированные на основе крылатых выражений, афоризмов, паремий прецедентные тексты (ср. другие используемые термины: прецедентные высказывания, выражения и т.д.) - это потенциально автономные смысловые блоки речевого произведения, которые актуализируют важную для автора фоновую информацию, апеллируя к «культурной памяти» читателя [Баженова 2006, 107]. Подобные прецедентные тексты приобретают в данной культуре прагматические «приращения»; наблюдаемая активизация деформации прецедентных текстов - отражение диалогичности современных публицистических текстов «с помощью приемов цитирования, аллюзий, реминисценций, ссылок, парафраз, пародий, которые способствуют формированию у читателя дополнительных ассоциаций» [Дускаева 2003, 670].

Отнесенность анализируемых в данной работе устойчивых выражений к ФЕ, а также их семантические, структурно-типологические, функционально-стилистические особенности определяются по словарям [Берков, Мокиенко, Шулежкова 2000; Большой фразеологический словарь русского языка 2006; Фразеологический словарь русского языка 1987].

\section{2. Проявление активных процессов фразеологии в русскоязычных газетах Литвы}

\section{Специфика использования ФЕ}

Рассматриваемые тексты относятся к разнообразным жанрам газетно-публицистического стиля: статьи, интервью, очерки, заметки, репортажи, эссе и т.д. Тематика данных текстов связана с жизнью 
страны и включает следующие рубрики: «Литва и мир», «Литва: события, факты», «Новости недели», «Новости экономики», «Общество», «Перекресток мнений», «Будни столицы», «Криминал, происшествия», «Дороги, машины, люди», «Музыка и театр», «Спорт». Как показывает наш материал, ФЕ обычно отмечаются в самих текстах, реже - в заголовках публикаций разной тематики, например: Надо omметить, что первая ласточка сыграла свою роль: жильцы еще одного из висагинских домов уже с нетерпением ожидают окончания модернизачии (...) (ЛК, № 34, 2019); Эрготерапия делает первые шаги (Эк.Н., № 2, 2019); А на фармакологическом рынке тем временем идет борьба за место под солнцем (Эк.Н., № 17, 2017); Вторая часть праздника - театрализованное представление - была интересна всем от мала до велика (Обз., № 29, 2019); Из первых $\boldsymbol{y c m}$ (название рубрики в газете Эк.Н.); Всевидящее око столиць (Эк.Н., № 46, 2017) - заголовок.

В рассматриваемых газетах активность использования ФЕ обусловлена дискурсом, характером информации (официальная-неофициальная), жанром текста, связанным с изложением материала, стилистической направленностью публикаций, индивидуальным стилем автора, спецификой самой газеты.

Так, фразеологизмы распространены более в социально-политическом дискурсе в авторских публикациях, полемических статьях с выраженной экспрессивностью, оценочностью: Даже не накопив нужной суммь, люди, соблазнившись перспективой светлого будущего, смело берут жилищнье кредить (...) (Эк.Н., № 23, 2019); Сектор розничной торговли пользуется ростом доходов граждан и поддается соблазну, повышая чены на некоторые товары. Зачем им рубить сук, на котором они сидят, если они могут заработать дополнительно? (Обз., № 19, 2019); Недвижимое имущество... Звучит красиво, но порой это камень на шее (Эк.Н., № 14, 2018) и др. Фразеологизмы обычно не используются в официальных новостях, информационных сообщениях, обзорах событий, передающих конкретную информацию.

Активность ФЕ отмечается также в жанре интервью или в текстах других жанров с целью передать живую речь собеседника: Фотомастер говорит: «Когда я иду по «своему» городу, я стараюсь смотреть в небо как можно дальше. Я приветствую вильнюсские костель. Когда я нахожу свои «точки» опоры, я гуляю со своими «учителями» (...) (ЛК, № 25, 2019); Известный телеведущий (...) так оченил в сочсети показ старой киноленть: «Поклонники филь- 
ма поясняют, что авторь хотели отразить тяжелое время, когда простье люди оказались меж двух огней (...)» (Эк.Н., № 20, 2019); «Когда заварили кашу с закрьтием парка, люди сотнями писали письма, просили: (...) держись, мьл с тобой (...)» (Эк.Н., № 20, 2019) и т.д.

Использование фразеологизмов как проявление индивидуальноавторского стиля журналиста демонстрирует следующий фрагмент публикации с заголовком «Экватор не пройден» (ср. перейти Рубикон), относящийся к спортивной тематике: Гости в очередной раз весьма доходчиво демонстрировали, что они не льком шиты и старье представления о силе встречавшихся в Вильнюсе команд давно пора отправить на свалку. (..) На второй тайм сборная Люксембурга выиила, судя по всему, с уверенностью в том, ито победа от них уже никуда не денется. Хозяева же, проведя довольно быстро все три заменьл, избрали тактику «пан или пропал», то и дело прессингуя в одиночку (в лучшем случае, в 2-3 игрока) защитников соперника (...) (Обз., № 24, 2019). Включение в контекст целого ряда ФЕ придает повествованию естественность, непринужденность.

Важно заметить, что по сравнению с современной российской публицистикой, где использование ФЕ возросло чрезвычайно, в текстах рассматриваемых газет наблюдается умеренное использование $Ф Е$; степенью же интенсивности включения ФЕ в тексты несколько выделяется стиль газеты «Экспресс-неделя».

\section{Структурно-типологические особенности ФЕ}

В анализируемых газетных текстах в ряду разнообразных типов ФЕ - преимущественно различные фразеологические обороты, например: Однако экспертьл не понимают, почему Министерство охрань окружающей средь подвергает дискриминации дизельнье автомобили. Они отмечают, что под одну гребенку стригут и старье, и новье экологичные дизельнье автомобили (Обз., № 30, 2019); Мотив такого поведения чаще всего один и тот же: несмотря на то, что из-за обилия автомобилей яблоку негде упасть, владелеи гаража эгоистично думает, что у него есть привилегия ездить так, словно на площадке нет ни одной машинь (Эк.Н., № 23, 2019); Уних есть сбережения на «черный день», но при этом нет ошущения стабильности и защищенности (Эк.Н., № 9, 2017); Mьл стараемся, чтобь жителям и гостям столищь не пришлось в праздничные дни ломать 
голову, как передвигаться по городу, и не терять время в пробках (Эк.Н., № 52, 2017) и под.

В меньшей степени используются:

- различные крылатые выражения и созданные на их основе прецедентные высказывания:

обычно из русской художественной литературы (из произведений И.А. Крылова, А.С. Грибоедова, А.С. Пушкина, М.Ю. Лермонтова, А. Григорьева, В.В. Маяковского, И. Ильфа и Е. Петрова): У нас есть возможность стать окном в Европу (...) (Эк.Н., № 52, 2017) - ср. выражение из поэмы А.С. Пушкина «Медный всадник»: $B$ Eвропу прорубить окно; Электромобили - наше все... (Обз., № 29, 2019) - ср. выражение А. Григорьева: «Пушкин - это наше все»; Планов громадье (Эк.Н., № 2, 2019) - ср. выражение из поэмы В.В. Маяковского «Хорошо»: Я планов наших люблю громадье;

реже - из популярных российских кинофильмов, песен эпохи XX в.: (...) чель поправок - обеспечить семьям максимальную безопасность, чтобь детей не могли отнимать «легким движением руки» (Эк.Н., № 2, 2019) - фраза из кинофильма «Бриллиантовая рука»; Эx, дороги, пьлль да туман... (ЛК, 2018) - фраза из песни «Дороги»); другие устойчивые выражения: фразы известных политиков, библейские, а также античные выражения, например: Рынок недвижимости в Литве на данный момент переживает свой «золотой век»: развивают новые проекты, чень растут, а люди берут ипотечные кредиты и покупают недвижимость (Обз., № 30, 2019);

- паремии: «C другой стороньл, нет худа без добра: сейчас самое время собрать из рек мусор. Этой ситуаиией может воспользоваться Министерство окружающей среды», - добавляет он (Эк.Н., № 20, 2019); Сейчас выскказывание «время-деньги» актуально как никогда. Именно по этой причине все больше успешных людей решают воспользоваться услугой собачьих нянь (Эк.Н., № 23, 2019); На страничах изданий и на порталах описань страсти-мордасти (...) (Эк.Н., № 30, 2019); заголовок - У семи нянек дитя без глаза (Эк.Н., № 15, 2017) и др.

Различия между фразеологическими оборотами, с одной стороны, и крылатыми выражениями, афоризмами, паремиями, с другой стороны, очевидны в их употреблении, структуре. Так, если фразеологические обороты отмечаются в публикациях, относящихся к разным дискурсам, то крылатые выражения, паремии и созданные на их основе прецедентные выражения более распространены в текстах социально-политического дискурса, например: Копить на старость смо- 
$\boldsymbol{л о д \boldsymbol { y } ( Л К , ~ № 2 4 , ~ 2 0 1 9 ) ~ - ~ з а г о л о в о к ~ с т а т ь и ~ о б ~ у ч а с т и и ~ в ~ д о п о л н и т е л ь н о м ~}$ пенсионном накоплении; ср.: береги честь смолоду; (...) шаткость (...) конструкции сильно преувеличена «блаженными верующими» (...) (Эк.Н., № 24, 2019) - ср. выражение из пьесы «Горе от ума» А.С. Грибоедова: Блажен, кто верует, тепло ему на свете!

Фразеологические обороты менее распространены в заголовках (подзаголовках), например: Расследование зашло в тупик (Обз., № 24, 2019); Телячьи нежности не для бизонов (Эк.Н., № 25, 2019); Отбился от рук (Эк.Н., № 7, 2017); Обратная сторона меда$\boldsymbol{л и ~ ( Э к . Н . , ~ № ~ 1 9 , ~ 2 0 1 7 ) . ~ Н а п р о т и в , ~ к р ы л а т ы е ~ в ы р а ж е н и я , ~ п а р е м и и ~}$ обычно являются заголовками текстов: Дареному коню в зубы не cмотрят (Эк.Н., № 34, 2019) - статья о бесплатной школьной форме для учеников из малоимущих семей; Где тонко, там и рвется (Эк.Н., № 35, 2019) - подзаголовок, о проблемах в той сфере, где человек наиболее уязвим; «Печально я гляжу...» (Обз., № 29, 2019) - о неудачах литовских футболистов (ср. выражение из стихотворения М.Ю. Лермонтова «Дума»: Печально я гляжу на наше поколенье) и мн. др. Выбор автором публикации в качестве заголовка определенной ФЕ помогает сразу определить отношение к предоставленной информации, создать подтекст - юмористический, иронический, саркастический. Однако, судя по нашему материалу, в основном целью заголовков является точное описание освещаемых событий, и, соответственно, заголовки публикаций преимущественно информативные. При этом сравним: фразеологизмы широко распространены в газетных заголовках, названиях традиционных рубрик прессы в российских и других СМИ [см., например, Павловская 2000].

Структурные особенности ФЕ связаны с их трансформацией. Основные виды структурной трансформации фразеологизмов таковы:

замена компонентов: (...) содержат своими налогами государство и поддерживают тем самым на плаву малоимущих (Эк.Н., № 2, $2019)$ - ср.: быть, оставаться, держаться на плаву; Для нас как государства очень важно шагать в ногу с прогрессом (ЛК, № 26, 2019) - ср.: идти в ногу; Деньги на свалку (ЛК, № 26, 2019) - ср. деньги на ветер ; Боремся с ветряными мельницами? (Эк.Н., № 15, 2017) - ср.: сражаться с ветряными мельницами;

расширение состава: Так что действительно хочется поставить финальную точку и сказать, что город не только толерантен $к$ таким парадам, но и рад, что они есть (...) (Эк.Н., № 23, 2019) - ср.: поставить точку; Вновь разгорелись страсти вокруг Зеленого моста. Немало копий было сломано (Эк.Н., №23, 2019) - ср.: 
ломать копья; Разумеется, каждая группа общества представляет по-своему, как следует вести дела, поэтому политика - это постоянный поиск компромисса в борьбе разных интересов, итобы, как гласит пословича, и волки были сыты, и овцы цель, а желательно, чтобы и овцы тоже были сытыл (Эк.Н., № 34, 2019);

сокращение состава: $\boldsymbol{C}$ глаз долой (Эк.Н., № 35, 2019) - ср.: с глаз долой, из сердиа вон (подзаголовок, о снижении масштаба использования личного транспорта); Чем богаты (Эк.Н., № 35, 2019) - ср.: чем богаты, тем и paдbl (подзаголовок, о залежах нефти на дне Балтики); и др.

Довольно часто происходит структурная трансформация крылатых выражений, паремий, афоризмов, характерных для заголовков; кроме того, виды их деформации более разнообразны и включают, например, пунктуационно-синтаксические средства:

фразы с многоточием для выражения незаконченности высказывания - Чтобы тело и душа были молоды... (Эк.Н., № 46, 2017) - из песни «Спортивный марш»; Чтобы костюмчик сидел... (Эк.Н., № 9, 2017) - из песни к кинофильму «Чародеи»;

вопросительные предложения: Век живи, век уиись? (Эк.Н., № 32, 2018); Без вины виноватые? (Эк.Н., № 3, 2018) - название пьесы А.Н. Островского;

парцелляция и замена компонентов: Великолепная семерка. И все! (Обз., № 32, 2019) - ср.: фраза Великолепная пятерка и вратарь из песни «Трус не играет в хоккей»; и др.

\section{Функционально-стилистические особенности ФЕ}

Значительная часть ФЕ, как известно, стилистически окрашена, и использование стилистически разнообразных ФЕ также является важным приемом выразительности в анализируемых газетных текстах. При этом разные типы ФЕ - фразеологические обороты и крылатые выражения, паремии - отличаются в стилистическом плане.

Фразеологические обороты в газетных публикациях обычно имеют окраску функционально-стилистическую:

- распространены разговорные фразеологизмы, придающие повествованию раскованность и непринужденность: Не до конца также ясно, какие государственные полномочия и функиии (...) передадут находящейся в Вильнюсе Литовской администрации безопасности на транспорте, где морских спечиалистов раз-два и обчелся (ЛК, № 46, 2018); Многие мужчинь, по его словам, не выдерживают 
и возвращаются домой несолоно хлебавши (Эк.Н., № 25, 2019); И только через год дошли руки до того, чтобь серьезно взяться за изучение литовского языка (...) (Эк.Н., № 25, 2019) - ср.: руки не доходили; На первых порах эта деятельность была дополнительной (...) (Эк.Н., № 23, 2019);

для того, чтобы подчеркнуть в контексте необычность выражения, его разговорный характер, используются кавычки: $У$ одних денег «полный мешок», а у других «кот наплакал», так и стали бывшие добрые соседи злейшими врагами. Именно по этой причине стоят сейчас многие старые многоквартирки с худыми крышами и обветшальми фасадами (ЛК, № 24, 2019); Сложно сказать и прогнозировать, что еще на этот раз «выссосут из пальца» (Эк.Н., № 23, 2019);

- фразеологические обороты с книжной окраской, создающие образность и выразительность текста: Это ахиллесова пята многих мегаполисов не только Европьи, но и мира (Эк.Н., № 18, 2017); В будущем у юристов не останется той рутинной работы, на которую они тратят сейчас львиную долю своего рабочего времени (Эк.Н., № 2, 2019); А вот тема планирования пенсии стала камнем преткновения для отвечавших: 22\% респондентов не ответили ни на один вопрос по этой теме (Эк.Н., № 23, 2019).

Значительно реже отмечаются фразеологические обороты с эмоционально-экспрессивной окраской. См., например, «неодобрительно», «грубо»: Мы только пишем проекты, ищем финансирование для них. Наивнылм людям просто промьвают мозги (...) (Эк.Н., № 25, 2019); посредством фразеологизмов, выступающих в контексте в эмоционально-оценочной функции, демонстрируется отношение к чему-либо: (...) какая из природных стихий сильнее бьет по карману государства, да и по нашему с вами карману (Эк.Н., № 25, 2019); Итак, легендарныи кинотеатр «Летува» стерт с лица земли (Эк.Н., № 15, 2017). Обратим внимание на то, что использование фразеологических оборотов жаргонного, грубо-просторечного характера нетипично для текстов рассматриваемых газет, в то время как в российских СМИ активизация стилистически сниженной фразеологии это проявление стремления к свободе выражения, к повышенной экспрессивности [например, Баско 2016].

В отличие от фразеологических оборотов, крылатые фразы, паремии и созданные на их основе прецедентные высказывания, наряду с окраской функционально-стилистической (часто - книжной, публицистической), обычно имеют эмоционально-экспрессивную окраску: 
- ироническую, саркастическую: (...) семь членов Верховного суда вынесли повторный и как бы окончательный вердикт: Карфаген, то есть злосчастная «усадьба Виюнеле», должен быть разрушен (Обз., № 30, 2019) - книжн., ирон. (античное выражение); Но, как у нас это часто бывает, хотели, как лучше, а получилось, как всегда (...) (Эк.Н., № 52, 2017) - разг., ирон. (фраза российского премьер-министра В.С. Черномырдина);

наиболее ярко ирония и сарказм выражается в заголовках: $\boldsymbol{B} \boldsymbol{c e} \boldsymbol{в \boldsymbol { b } -}$ ше, и вылие, и вышие... (Эк.Н., № 20, 2019) - о повышении цен в сфере услуг (из песни «Авиамарш», ср.: Bcе вылие, и вылее, и выле стремим мы полет наших птии); Впереди Европь всей (Эк.Н., № 35, 2019) - о размерах банковских прибылей (ср.: фраза из песни Ю. Визбора впереди планеть всей); Неисповедимь пути денежек наших? (Обз., № 25, 2019) - о государственном бюджете (ср. изречение из Нового завета Неисповедимь пути господни); $\boldsymbol{A}$ прокуратура и ньне maм (Обз, № 36, 2019) - о том, что прокуратура не занимается делом погибшей (ср.: выражение $A$ воз и ныне там из басни И.А. Крылова «Лебедь, Щука и Рак»); Выљбираем кота в мешке (Эк.Н., № 35, 2019) - о выборе жильцами многоквартирного дома администратора (ср.: noкупать кота в мешке);

- реже отмечается окраска неодобрительная: (...) может ли позволить себе страна (...) строить новый железный занавес (Эк.Н., № 25, 2019) - публ., полит., неодобр. (выражение из речи У. Черчилля); шутливая: Пластиковые пакеты: былть или не быть... (Эк.Н., № 33, 2018) (известное выражение из трагедии В. Шекспира «Гамлет»).

В целом же в текстах анализируемых газет экспрессия и оценочность выражается умеренно; эмоционально-оценочные ФЕ обычно включаются в такие публикации, где демонстрируется субъективное отношение автора к той или иной проблеме.

\section{Культурно-речевые особенности ФЕ}

Использование разнообразных ФЕ делает информацию газетных текстов более доступной и интересной для читателя. Вместе с тем можно заметить определенную «речевую моду» журналистов на те или иные фразеологизмы, частотное использование некоторых $Ф Е$ в текстах разных авторов, например:

перегибать палку - Однако стоимость некоторых услуг (...) уже достигла предела. Они должны расти, но не нужно перегибать палку (Эк.Н., № 20, 2019); (...) обещает не перегнуть палку, 
чтобы не нанести удар по кошелькам малоимущих слоев населения (Эк.Н., № 23, 2019);

среди (средь) бела дня - Там жулики в считанные минуть средь бела дня даже на иентральньх уличах, где много камер наблюдения, могут вскрыть машину (Эк.Н., № 33, 2018); Особенно страдают послушные дети, их даже среди бела дня преступники без лишнего шума берут за руку и уводят (Эк.Н., № 24, 2019);

иувство локтя - Но зато он помогает ошутить «иувство локтя» (Эк.Н., № 34, 2019); Должно быть иувство локтя (Эк.Н., № 2, 2019) - подзаголовок;

пословица «На зеркало неча пенять, коли рожа крива»: Так ито проблема не в том, ито где-то там есть заболеваемость (тьл ведь и сам сегодня можешь заразить болезнью жителя любой другой страны), а в том, что мь потеряли бдительность. Как говорится, неча на зеркало пенять, коли рожа крива (Эк.Н., № 24, 2019); Не надо на других пенять... (Эк.Н., № 46, 2017) - заголовок.

Заметим, что целый ряд повторяющихся в нашем материале ФЕ, приводящих к некоему стилистическому однообразию, отмечается и в исследованиях языка российских и других русскоязычных СМИ [ср., например, Павловская 2000, Баско 2016]: быть или не быть; все выше, и выше, и выше; прорубить окно в Европу; хотели как лучше, а получилось как всегда; козел отпущения; зайти в тупик; камень преткновения; бить по карману; держаться на плаву и др. Возможно, в таком повторе определенных $Ф Е$ находят в языке отражение лингвокультурологические особенности языковой личности нашего времени.

Необходимо обратить внимание и на то, что неточное понимание семантики, структуры, специфики употребления фразеологизма может привести к нарушениям речевой нормы, которые, к сожалению, встречаются в текстах рассматриваемых газет. Например, вряд ли уместно использование следующего фразеологизма в подзаголовке статьи о мелиорации: Канавы как козль отпущения (Эк.Н., № 24, 2019) - ср. обычную сочетаемость фразеологизма с одушевленным существительным в значении «человек, на которого сваливают чужую вину, ответственность за других»: (...) людей, на законном основании купивших недвижимость, превратили в козлов отпущения (Эк.Н., № 17, 2017). Трансформация ФЕ также далеко не всегда является приемом создания выразительности; в некоторых случаях это речевая ошибка, связанная: а) с заменой близких по значению компонентов сочетаний: Заядлье грибники уже списали со счетов этот сезон 
(Эк.Н., № 25, 2019) - ср.: сбрасывать со счетов или списать в расход); б) с утратой компонентов: Некоторые линии шатко - валко действуют, но в 40\% не налажена обратная связь (Эк.Н., № 19, 2017) - ср.: ни шатко ни валко.

\section{3. Заключительные замечания}

В ряду активных процессов, происходящих в русском языке новейшего периода, и прежде всего в языке СМИ, весьма значительна роль фразеологии. Активные процессы фразеологии, характерные для публицистического стиля современного русского языка, находят специфическое отражение в текстах русскоязычных газет Литвы. Региональные особенности подобных процессов связаны со степенью их интенсивности и касаются активности употребления и специфики функционирования в текстах газет $\Phi \mathrm{E}$, их структурно-типологических, а также стилистических черт, выражения авторской оценочности.

В анализируемых текстах, в отличие от газетных публикаций в российских СМИ, наблюдается умеренное использование ФЕ и выражение экспрессии. Это может быть обусловлено экстра- и лингвистическими факторами, определяющими социокультурную и жанровую специфику рассматриваемых газет в данной социолингвистической ситуации и, соответствено, языковые особенности газетных текстов.

Как показывает анализируемый материал, ФЕ отмечаются в газетных публикациях различных жанров и в различных дискурсах, но чаще - в социально-политическом дискурсе в авторских статьях. В ряду разнообразных структурных типов ФЕ доминируют фразеологические обороты. В меньшей мере используются крылатые выражения, паремии и созданные на их основе прецедентные выражения, которые обычно встречаются в заголовках текстов, представляя собой разнообразные структурные деформации и выделяясь яркой стилистической окраской - как функционально-стилистической, так и эмоционально-экспрессивной.

Фразеологизмы в публицистическом дискурсе являются важным средством создания выразительности языка, авторского самовыражения, привлечения внимания читателей, однако в некоторых случаях включение ФЕ в газетные тексты может приводить к стилистическим ошибкам и отступлениям от речевой нормы, обусловленным недостаточным владением фразеологическими ресурсами языка. 


\section{Литература}

Baženova E.A., 2006, Intertekstual'nost', [v]: Stilističeskij ènciklopedičeskij slovar'russkogo âzyka, Moskva, s. 104-108. [Баженова Е.А., 2006, Интертекстуальность, [в]: Стилистический энииклопедический словарь русского языка, Москва, с. 104-108.]

Basko N.V., 2016, Frazeologizmy v âzyke sovremennyh rossijskih SMI: leksikografičeskoe opisanie, Moskva. [Баско Н.В., 2016, Фразеологизмы в языке современных российских СМИ: лексикографическое описание, Москва.]

Berkov V.P., Mokienko V.M., Šuležkova S.G., 2000, Bol'šoj slovar' krylatyh slov russkogo âzyka, Moskva. [Берков В.П., Мокиенко В.М., Шулежкова С.Г., 2000, Большой словарь крылатых слов русского языка, Москва.]

Bol'šoj frazeologičeskij slovar' russkogo âzyka. Značenie. Upotreblenie. Kul'turologičeskij kommentarij, 2006, Moskva. [Большой фразеологический словарь русского языка. Значение. Употребление. Культурологический комментарий, 2006, Москва.]

Vencel' K., 1998, Idiomy v russkom političeskom diskurse, Rusistika segodnâ, № 1-2, Moskva. [Венцель К., 1998, Идиомь в русском политическом дискурсе, Русистика сегодня, № 1-2, Москва.]

Duskaeva L.R., 2006, Âzykovo-stilističeskie izmeneniâ v sovremennyh SMI, [v]: Stilističeskij ènciklopedičeskij slovar' russkogo âzyka, Moskva, s. 664-675. [Дускаева Л.Р., 2006, Языково-стилистические изменения в современных СМИ, [в]: Стилистический энииклопедический словарь русского языка, Москва, с. 664-675.]

Zelenin A., 2007, Âzyk russkoj èmigrantskoj pressy (1919-1939), Sankt-Peterburg. [Зеленин А., 2007, Языю русской әмигрантской прессь (1919-1939), Санкт-Петербург.]

Kostomarov V.G., 1994, Âzykovoj vkus èpohi. Iz nablûdenij nad rečevoj praktikoj mass-media, Moskva. [Костомаров В.Г., 1994, Языковой вкус эпохи. Из наблюдений над речевой практикой масс-медиа, Москва.]

Mokienko V.M., 2017, Frazeologiâ v sovremennoj publicistike, [v]: Slavânskâa frazeologiâ v sovremennyh SMI (publicističeskij diskurs), Kollektivnaâ monografiâ, Grajfsval'd - Sankt-Peterburg - Zagreb, s. 26-36. [Мокиенко B.M., 2017, Фразеология в современной публичистике, [в]: Славянская фразеология в современных СМИ (публичистический дискурс), Коллективная монография, Грайфсвальд - Санкт-Петербург - Загреб, с. 26-36], [online] http://phraseoseminar.slovo-spb.ru/documents/monografija_neu_14_febr.pdf [20.07.2019].

Pavlovskaâ L.P., 2000, Frazeologizmy v zagolovkah russkih latvijskih gazet, [v]: Trudy po russkoj i slavânskoj filologii, Lingvistika, Tartu, s. 205-213. [Павловская Л.П., 2000, Фразеологизмьв в заголовках русских латвийских газет, [в]: Труды по русской и славянской филологии, Лингвистика, Тарту, c. 205-213.] 
Protasova E.Û., 2004, Fennorossy: žizn' $i$ upotreblenie âzyka, Sankt-Peterburg. [Протасова Е.Ю., 2004, Феннороссы: жизнь и употребление языка, Санкт-Петербург.]

Russkij âzyk konca XX stoletiâ (1985-1995), 1996, Moskva. [Русский язык конца ХХ столетия (1985-1995), 1996, Москва.]

Slavânskâ̂ frazeologiâ v sovremennyh SMI (publicističeskij diskurs), 2017, Kollektivnaâ monografiâ, Grajfsval'd - Sankt-Peterburg - Zagreb. [Славянская фразеология в современных СМИ (публичистический дискурс), 2017, Коллективная монография, Грайфсвальд - Санкт-Петербург - Загреб], [online] http://phraseoseminar.slovo-spb.ru/documents/monografija_neu_14_ febr.pdf [20.07.2019].

Sternin I.A., 2003, Social'nye faktory i publicističeskij diskurs, [v]: Massovaâ kul'tura na rubeže $X X-X X I$ vekov. Celovek $i$ ego diskurs, Sbornik naučnyh trudov, Moskva, s. 91-108. [Стернин И.А., 2003, Социальные факторы и публицистический дискурс, [в]: Массовая культура на рубеже XX-XXI веков. Человек и его дискурс, Сборник научных трудов, Москва, с. 91-108.]

Teliâ V.N., 1998, Frazeologiâ, [v]: Âzykoznanie. Bol'šoj ènciklopedičeskij slovar', 2-e izd., Moskva, s. 560-561. [Телия В.Н., 1998, Фразеология, [в]: Языкознание. Большой энчиклопедический словарь, 2-е изд., Москва, с. 560561$.

Frazeologičeskij slovar' russkogo âzyka, 1987, 4-e izd., stereotip., Moskva. [Фразеологический словарь русского языка, 1987, 4-е изд., стереотип., Москва.]

Šapošnikov V., 1998, Russkaâ reč' 80-h gg., Moskva. [Шапошников B., 1998, Pycская речь 80-x г2., Москва.]

ACTIVE PROCESSES IN THE PHRASEOLOGY

(ON THE MATERIAL OF RUSSIAN-LANGUAGE NEWSPAPERS IN LITHUANIA)

ABSTRACT

Key words: phraseology, active processes, regional features, newspaper texts

Active processes taking place in all areas of the Russian language during the last decades are most clearly manifested in the language of the media. Among the expressive means of the media language, a special place is held by phraseology, which emphasizes the relevance of the information provided, has a strong emotional effect on readers. In this regard, the purpose of this article is to consider some manifestations of the active processes of phraseology in the Russian-language newspapers of Lithuania. The study material is the weekly "Литовский курьер" ("Lithuanian Courier"), "Обзор" ("Review"), "Экспресс-неделя" ("Express Week").

The active processes of phraseology, characteristic for the journalistic style of the modern Russian language, are specifically reflected in the language of the newspapers analysed. The regional specific features of these processes are associated with the activity of use and the specifics of the functioning of phraseological units in newspaper texts, their structural-typological, stylistic features, expressiveness and expression of the author's appraisal. 